\title{
THE PATHOLOGY OF BLADDER TUMOURS
}

\author{
By R. C. B. Pugh, M.D. \\ Pathologist to St. Peter's, St. Paul's and St. Philip's Hospitals, and the Institute of Urology, London
}

Over 90 per cent. of the tumours that occur in the urinary bladder take origin from the mucous membrane and the remainder are a miscellaneous group that includes the benign and the malignant connective tissue tumours, as well as metastases from primary growths occurring elsewhere in the body. The bladder wall may also be invaded in continuity by a tumour arising in an adjacent structure, such as the rectum or cervix uteri.

\section{Epithelial Tumours}

It has to be appreciated that the bladder is but a part of a relatively large area that is lined throughout by transitional epithelium and comprises, in addition to the bladder itself, the renal pelves, the ureters and part of the urethra. In some instances, tumour formation is limited to the bladder but this is by no means always the case. It therefore follows that serious diagnostic errors can only be avoided if the investigation of a patient suspected of having or known to have a bladder growth includes assessment of the condition of the whole of the urinary tract by every means possible-such as urine culture, excretion urography, urethroscopy, cystoscopy, biopsy and bimanual examination under full anaesthesia (Wallace, 1956).

The manner in which multiple tumours may arise is a controversial problem that has not yet been satisfactorily resolved and the current theories-of multicentric origin (Willis, 1953), of urogenous production (Wallace, 1956), of superficial spread in the submucosal lymphatics and of implantation metastasis-all have their protagonists and are each supported by much clinical and/or experimental evidence. In particular, the possibility of implantation metastasis has always to be considered in relation to therapy as it is a hazard of bladder surgery. After perurethral instrumentation, for example, it may occur on a raw surface in the urethra or prostatic bed (Melicow, 1955; Boreham, 1956) and it is also seen in the abdominal wall after cystostomy or partial cystectomy (Hollands, 1950; Cooling, 1955). In a unique case reported by Riches and Page (1956) implantation occurred in the colon following cystectomy and uretero-sigmoidostomy.

\section{Frequency, Sex and Age Incidence}

Carcinoma of the bladder accounts for about three per cent. of all fatal malignant new growths (Registrar General, 1954) and is one of those tumours whose incidence, in this country at any rate, is on the increase (Wallace, 1956). The majority of cases present in middle to late life and males are affected three times as frequently as females (Harnett, 1952; Steiner, 1954).

\section{Possible Predisposing Factors}

Tumour formation is a well-recognized complication of vesical exstrophy, when it usually takes the form of an adeno-carcinoma (Scott and Sorbie, 1956). As discussed later, it may also commence in one of the proliferative "pre-cancerous' lesions of the mucosa and is well known as an industrial hazard too, occurring after exposure to such substances as $\beta$-naphthylamine, benzidine or xenylamine (Melick, et al., 1955). Its association with schistosomiasis is not proven (Willis, 1953; Steiner, 1954).

Recent work has suggested that a urogenous factor may sometimes be significant and it is believed that any such stimulus is likely to be more potent when it is coupled with urinary stasis. The finding of evidence of present or past stasis in the urinary tract in 20 per cent. of all male patients in a large seric : of cases of bladder cancer is, therefore, of particular interest and possible relevance (Wallace, 1956). Tryptophane is also concerned in some way with this mechanism, as shown by the fact that its addition to a carcinogenic diet may cause localization of tumours to the bladder in the experimental animal (Boyland, Harris and Horning, 1954). It is also of interest that the urine of patients with bladder cancer sometimes contains an excess of certain enzymes, which are capable of transforming the usual non-carcinogenic metabolites of tryptophane into abnormal products that can themselves produce local tumours when implanted into the bladder of mice (Bonser, Clayson, Jull and Pyrah, 1954; Boyland and Williams, 1955; Boyland and Watson, 1956).

\section{Macroscopic Appearances}

The tumours, which may be single or multiple, 
occur most often in the base of the bladder in the region of the trigone and the ureteric orifices. Usually they have a pedunculated or papillary appearance but may present as sessile, nodular or ulcerated lesions.

The adjacent mucosa is frequently atypical and shows one or more of the proliferative 'precancerous' changes or may be raised up by many nodules of lymphoid tissue in the submucosa, producing a lesion that often closely resembles cystitis cystica when seen through the cystoscope. The precise significance of this submucosal lymphoid hyperplasia is not known.

\section{Microscopic Appearances and the Institute of Urology Classification of Tumours}

The epithelial tumours of the bladder exhibit such a wide range of structure that clear separation into benign and malignant forms on purely histological grounds is not always possible, and it is more convenient to consider them as a single group with all gradations from the benign papilloma on the one hand to the invasive anaplastic carcinoma on the other. Furthermore, the histological appearances are better understood if it is recognized that the bladder epithelium has an especial tendency to produce certain proliferative lesions or to undergo metaplasia in response to a variety of stimuli, including infection, chronic irritation, trauma and chemical action. The proliferative lesions-such as polypoidal cystitis, von Brunn's nests, epithelial clefts and cystitis cysticaare probably benign but their very frequent association with spontaneously occurring or experimentally produced bladder tumours has led to the widely-held belief that they should be considered as pre-cancerous lesions (Mostofi, 1954; Johnson, 1957). The term metaplasia is used to denote an alteration of the transitional cells into either a squamous or a columnar cell epithelium, which may or may not secrete mucus. Combined forms commonly occur and, rarely, a cuboidal type of epithelium may be seen (Mostofi, 1954). As might be expected these metaplastic tendencies are also met with in bladder tumours, which may thus have either a pure transitional cell, squamous cell or glandular pattern, or may contain some or all of these elements in a mixed structure.

Much of the difficulty in arriving at a clear understanding of the pathology of bladder cancer lies in the fact that there is, as yet, no universally accepted classification of this group of tumours. Of the many schemes already in use it is probably true to say that no single one is absolutely ideal, although each has its merits and serves to emphasize one or more of the important factors and facets of tumour behaviour. It is equally unfor- tunate that there is often a measure of overlap between the various systems so that an individual tumour may be given a different name-and possibly acquire a slightly altered significance-when it is classified by more than one method. This is particularly true of the papilloma and much of the controversy and difficulty in comparing the different classifications centres round the identification of the benign tumour and the means of distinguishing it from the well-differentiated carcinoma. Until uniformity is achieved this confusion will continue and satisfactory comparisons between the results of cases seen and treated in different centres will not be possible.

A full discussion of all the different systems of classification cannot be undertaken here and it is proposed to describe in detail the Institute of Urology scheme, published by Dukes in 1955, and to refer to the more important of the others quite briefly.

The fundamental point of Dukes' classification is that it is a clinico-pathological one in which the histological ' grading ' of a tumour, which describes its pattern and cell structure, is correlated with the clinical 'staging,' which defines the extent to which the growth has spread into the bladder wall and surrounding structures. The determination of the one without the other is valueless. The clinical staging, which is obtained from full clinical examination of the patient-including bimanual examination-can be assessed and re-assessed during the course of the disease and must bed istinguished from the 'pathological staging', which is defined in the laboratory after examination of operation specimens. Clearly, the pathological staging will be incomplete when only biopsy material is available and will increase in accuracy and value with larger specimens. The original Institute of Urology classification (Dukes and Masina, 1949) took account of the pathological staging but the modification now in use (Dukes, 1955) puts rather more emphasis on the clinical staging. However, there is usually a very satisfactory measure of agreement between the two and the pathological staging is a very useful check on the accuracy of the clinical assessment of the case.

The two features that decide the histological grade of a tumour are the pattern of the growth and the structure of the epithelium. Four basic tumour patterns are recognized (Fig. I): carcinoma in situ or intra-epithelial cancer, which are self-explanatory terms denoting a malignant change without alteration in the outline of the epithelium other than, possibly, some thickening; the papillary form, in which growth occurs towards and into the lumen of the bladder; the solid form, in which tongues of tumour grow into the submucosa and thence into and eventually 


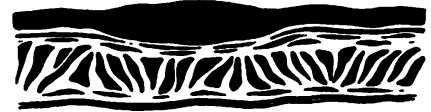

INTRAEPITHELIAL

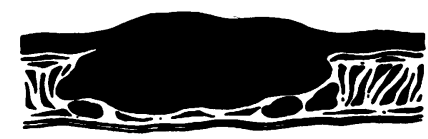

SOLID

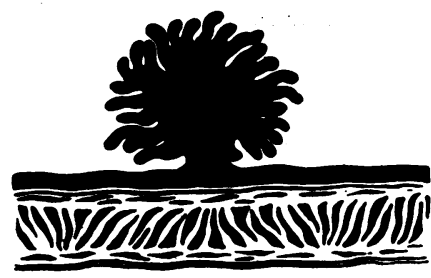

PAPILLARY

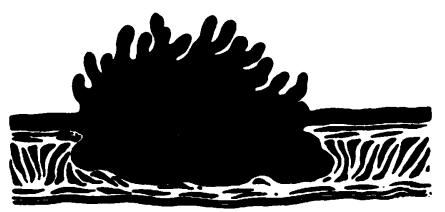

PAPILLARY and SOLID

Fig. I.-Patterns of tumour growth.

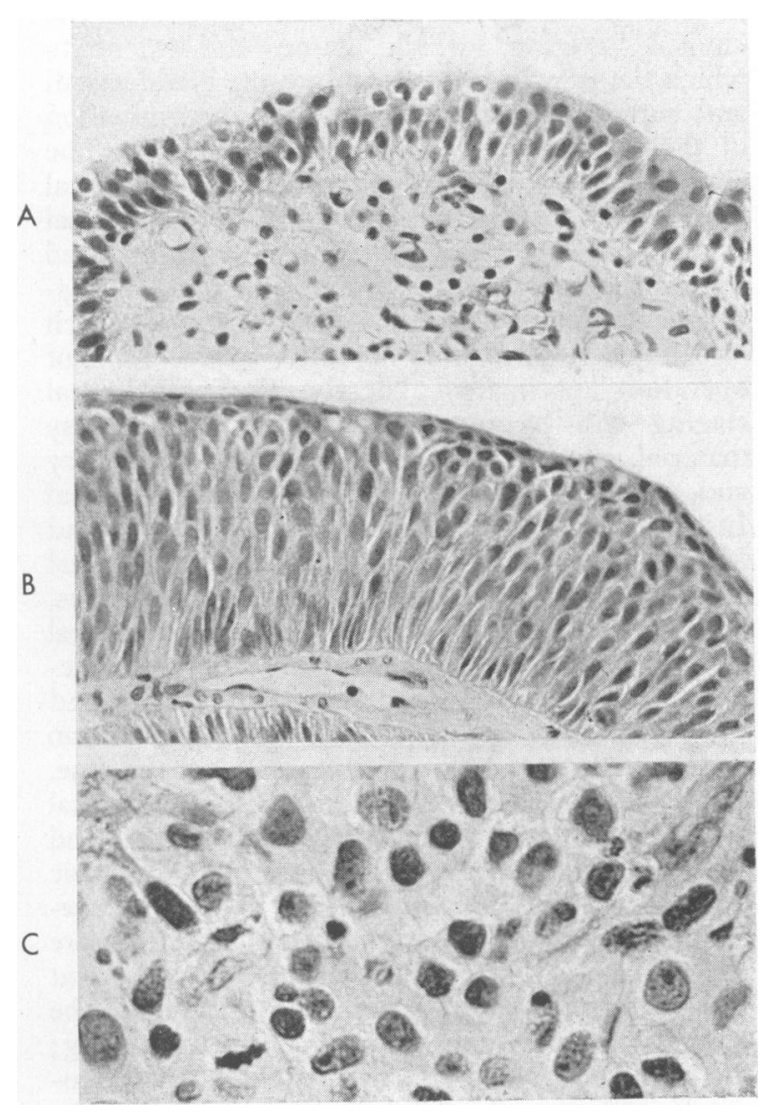

Fig. 2.-A, papilloma (x 400); B, differentiated carcinoma (x 400); C, anaplastic carcinoma (x 400). through the muscle coat of the bladder wall and, finally, the papillary and solid variety, which combines the features of the previous two types. This separation is of vital importance because it has been found that as soon as a tumour acquires a solid component its behaviour alters radically and the prognosis immediately worsens (see Fig. 3). With regard to the epithelium, there are many possible patterns but the classification recognizes only three fundamental structural variants, which are typified by the benign papilloma, the differentiated carcinoma and the anaplastic carcinoma (Fig. 2). In the papilloma there is a central fine connective-tissue core that supports a thin layer of regular transitional cells, which are in all respects identical with those seen in the normal bladder mucosa. In the differentiated carcinoma the epithelium varies quite considerably in thickness and regularity and, as compared with the papilloma, the cells are larger, often stain more darkly, are of irregular shape and contain mitotic figures. So long as the tumour cells can still quite clearly be recognized as having arisen from transitional epithelium the growth is included in the differentiated group, but as soon as this is no longer possible it is placed into the anaplastic group. Here the neoplastic cells vary very considerably in size, shape and staining and are often hyperchromatic or multi-nucleated. The cells are pleomorphic without any regular arrangement and bizarre cell forms and mitotic figures are numerous. When describing the grade of a tumour a combination of terms is used-e.g. papillary differentiated or solid anaplastic carcinoma-which indicate both the pattern of the growth and the structure of its epithelium. 
It is not claimed that histological grading is always an easy matter and difficulty inevitably arises with those tumours which do not readily fall into one or other group (i.e. the 'borderline' cases). For this reason alone this classification has particular merit, in that there are only two such groups of borderline cases, whereas in the more elaborate systems the number of equivocal tumours is likely to be larger. It is perhaps relevant at this point to emphasize that the successful interpretation of biopsy material depends as much on the proficiency of the surgeon who removes the specimen from the bladder as on the experience of the pathologist who examines the sections. Furthermore, and despite what is often said to the contrary (Melicow, 1946), the appearances are usually remarkably uniform throughout a tumour so that, if necessary, a tumour can often be successfully and adequately graded when only small portions of it have been removed by the surgeon. This is not to say that small biopsies are to be preferred, but they can frequently yield valuable information. In most instances, too, there is a satisfactory degree of agreement between the gradings obtained from preliminary biopsies and from subsequent operation specimens.

Two other forms of tumour that are met with occasionally are the squamous carcinoma and the adeno-carcinoma and, although rare, they merit some description. In the Institute of Urology classification, these terms are reserved for those tumours with a uniform histological appearance throughout and which have to be distinguished from the group of transitional cell tumours showing metaplasia to a squamous or glandular pattern. In the metaplastic group it is often the case that the squamous or glandular change is focal and the cells are imperfectly formed; mixed transitional, squamous and glandular patterns are thus quite common and the tumours are often very pleomorphic and bizarre in appearance. The reason for stressing this distinction is that there are significant behaviour differences in the two groups. The pure squamous tumour usually grows relatively slowly to fill the bladder completely, metastasizing late in the course of the disease to the regional lymph nodes, whereas metaplasia is a particular feature of the very anaplastic and highly-invasive transitional cell carcinomas, which grow rapidly into the bladder wall and often metastasize quite quickly to the regional lymph nodes. An interesting detail is that in the pure squamous tumour there is often a brisk stromal reaction around the tongues of tumour, which is a feature less frequently seen in the transitional tumour showing squamous metaplasia. Most of the adeno-carcinomas arise in the base of the bladder but occasionally occur at the dome where they ori-
Tabla.-InCidence of Histological Grades in $1,4,30$ Cases of Epithelial Bladder Tumour

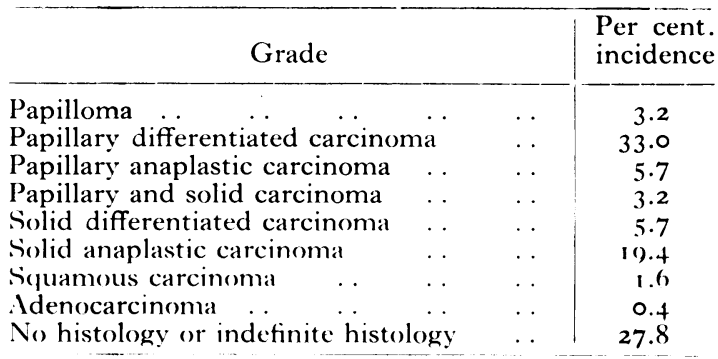

ginate, usually as colloid carcinomas, from the remnants of the urachus (Campbell Begg, I93 I). There is also a very high incidence of this type of tumour amongst the growths arising in the exstrophied bladder, which contrasts with its low incidence in the normally-developed bladder.

The Table shows the incidence, in a recent series of cases, of the various types of tumour that have so far been discussed. It will be noted that carcinoma in situ is not listed, for the reason that it is almost invariably accompanied by one of the other types of lesions and the very small number of cases in which it occurred alone does not warrant the formation of a separate group. The low incidence of papillomas also calls for comment. This is due to some extent to the histological definition (which excludes many tumours which would be called papillomas in other classifications) and partly to the fact that this series is a selected one, in that all the patients were seen in a group of specialized hospitals to which they were often referred, sometimes as problem cases, after having been seen and treated elsewhere. In contrast, the 'indefinite histology' group is a large one, principally because the experienced urologist usually makes a practice of fulgurating mucosal tumours as completely as possible rather than excising them for histological examination. It is likely that the bulk of the purely mucosal tumours treated in this way would have been proved to be papillomas or papillary differentiated carcinomas had they been examined histologically and it is a safe assumption that the true incidence of these two types of tumour is almost certainly higher than the figures quoted here would suggest.

Having thus far considered the histological grading, it is now necessary to discuss the clinical staging and then to correlate these two methods of assessment. The clinical stage is determined by a full examination of the patient, which must include excretion urography and a bimanual examination under full anaesthesia. It is beyond the scope of this article to comment on the details of the clinical methods used, but they are described fully elsewhere (Wallace, 1956). Four stages are 


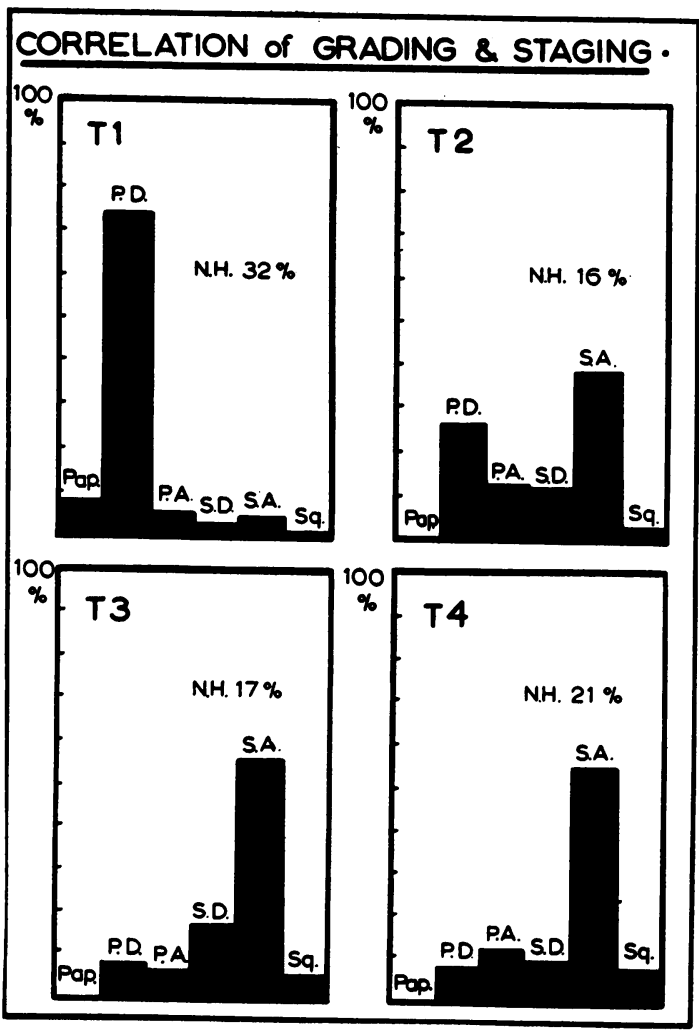

FIG. 3

recognized-the mucosal ( $\left.\mathrm{T}_{1}\right)$, the muscular ( $\left.\mathrm{T}_{2}\right)$, the perivesical $\left(\mathrm{T}_{3}\right)$ and, finally, the pelvi-fixation $\left(\mathrm{T}_{4}\right)$ - which denote the depth to which the tumour has spread into or beyond the bladder wall (Wallace, 1956). The practical importance of using a 'grading with staging' system at all is that the two are complementary and, together, give enough reliable information upon which to base a reasonably accurate prognosis. In Fig. 3 the different grades and stages are correlated and it will be seen, firstly, that all the papillomas and about three-quarters of the papillary differentiated carcinomas are in the $T_{I}$ clinical stage and, secondly, that with increasing penetration into the bladder wall the histological grade alters, so that there is an increase in the proportion of both solid and anaplastic tumours in the higher stages. Probably the three most important factors that can influence the prognosis in a case of bladder tumour are the site of the tumour, its histological grade and the clinical stage. As regards the site, the short distance that usually exists between a bladder tumour situated in the trigone (which is the commonest site for a tumour to occur) and the lower ends of one or both ureters may not only prevent adequate local resection, but also increases the risk of permanent damage and obstruction to the ureters either by the tumour itself or by scarring resulting from treatment. The grade and stage are significant, too, because plotting of the fiveyear survival rates, both by grade and by stage, shows that a reasonable survival rate is to be found only in tumours of the papillary differentiated grade (6o per cent. survival) or TI stage (6o to 70 per cent. survival). Anaplastic change in the epithelium, the appearance of a solid component in a tumour and penetration beyond the submucosa are all of sinister significance, and the five-year survival rates fall to $I 5$ per cent. in the papillary anaplastic, ro per cent. in the solid differentiated and 5 to ro per cent. in the solid anaplastic grades, and to 30 per cent., 15 per cent. and nil, respectively, in the $\mathrm{T}_{2}, \mathrm{~T}_{3}$ and $\mathrm{T}_{4}$ stages.

\section{Other Systems of Classification}

The classification which most closely resembles the Institute of Urology scheme is that of Marshall (1956), which relates the histological appearances of the epithelium-on much the same lines as in Broders's method (1922) - to the degree of penetration of the bladder wall as defined by Jewett and Strong in 1946. Four grades of tumour are recognized-the papilloma, low-grade and highgrade carcinoma and other tumours-as well as five pathological stages, which are very similar to the four clinical stages of the Institute classification, except that the muscular stage is divided into two, with the mid-point of the muscle as the dividing line between the " superficial ' and ' deep ' tumours. The superficial group have a reasonably good prognosis, very similar to that of the Institute's ' $T_{1}$ tumours, whereas the deep group have a very poor outlook, comparable to that of the $\mathrm{T}_{2}, \mathrm{~T}_{3}$ and $\mathrm{T}_{4}$ clinical stages.

In dividing bladder tumours into seven numbered groups, Franksson (1950) takes into account the differentiation of the epithelium and the integrity of its basement membrane. The depth of spread into the bladder wall is also emphasized as a prognostic factor but the vital point determining whether a tumour is likely to behave reasonably well or have a bad prognosis is thought to be penetration of the basement membrane. Once this has occurred the tumour is considered to be a dangerous one. When it is appreciated that rupture of the basement membrane is probably the earliest recognizable stage of the formation of a solid component in a tumour, it will be seen that Franksson's classification and the Institute scheme are not very far apart in their recognition of those tumours that are likely to have a bad prognosis. Whether the difference is a significant one is not yet known but is a point that would repay investigation. 
The Bladder Tumor Registry at the Armed Forces Institute of Pathology in Washington adopts the same criteria as the Institute of Urology for the diagnosis of a papilloma and recognizes three tumour patterns (papillary, infiltrating, papillary and infiltrating) and three numbered grades of carcinoma ( 1,2 and 3 ), which denote increasing de-differentiation of the epithelium. The infiltrating pattern corresponds to the solid pattern of the Institute of Urology classification and, in general terms, Grade I and Grade 2 tumours are equivalent to the differentiated and Grade 3 to the anaplastic tumours as they are defined above (Mostofi, 1957).

\section{Methods of Spread}

Spread may occur by direct continuity in the tissues of the bladder wall and, as already indicated, forms a useful basis for classifying bladder growths. Metastasis occurs more often with anaplastic than with differentiated tumours and is more frequent with those tumours that penetrate deeply into the bladder wall than in the ones which are entirely superficial. In the superficial tumours, dissemination may sometimes occur in a centrifugal manner in the lymphatics of the submucosa, producing 'seedlings' at the periphery of the main growth. Lymphatic metastases to the regional lymph nodes along the iliac vessels or the aorta occur in about one-third of fatal cases and, occasionally, small metastatic nodes are also found in the extravesical fatty tissues in total cystectomy or autopsy specimens. Haematogeneous dissemination, usually to the liver, lungs or skeleton, occurs late in the course of the disease and in about one-third of the fatal cases.

\section{Cause of Death}

The commonest single cause of death in bladder cancer is undoubtedly renal failure, due to obstruction to the outflow of urine because of involvement of the ureters in the primary tumour or its lymph nodal metastases at the pelvic brim (Cooling, 1955).

\section{Other Tumours}

\section{Benign Connective Tissue Tumours}

These are uncommon and many varieties, including myomas, fibromas, neurofibromas and angiomas, have been described (Herbut, 1952).

\section{Sarcoma}

These are also uncommon and account for about 0.5 per cent. of all bladder tumours (Pack and Le Fevre, 1930; Kretschmer and Doehring, 1939). In their recent survey, McCrea and Post (1955) found that $6 \mathrm{I}$ per cent. originated in muscle (leiomyosarcoma being more common than rhabdomyosarcoma), I7 per cent. were fibrosarcomas and $1_{5}$ per cent. reticulosarcomas. Mixed types also occur.

Leiomyosarcomas have their maximum incidence in the sixth decade and are twice as common in men as in women. The tumours occur anywhere in the bladder, although the trigone is usually spared, and may be single or multiple, and pedunculated or sessile. The overlying epithelium soon becomes ulcerated. Microscopically they consist of whorled masses of fusiform cells.

Rhabdomyosarcomas are tumours of childhood, which present in the first decade and usually within the first three years of life. Boys are affected more often than girls. The tumours arise from the base of the bladder and in boys may originate in the prostate as well. Macroscopically they are quite characteristic, with multiple rounded or polypoidal nodules of soft gelatinous consistency, which may obstruct the internal meatus or urethra and cause retention of urine. Microscopically the bladder mucosa is usually intact and the underlying tumour consists of a very cellular, myxoma-like tissue resembling embryonic connective tissue. Elongated 'rhabdomyoblasts,' in which cross-striations can usually be identified, occur in variable numbers. This is a highly malignant tumour of diffuse field origin (White, 1952) which, all too often, is mistaken for a benign myxoma. To be effective, treatment must be radical and prompt.

Fibrosarcomas occur at all ages and at all sites and do not merit further description.

Reticulosarcomas occur in middle to late life and may be isolated lesions or may occur as a terminal manifestation in a systematized disorder. Single or multiple lesions can occur in the bladder and many histological variants, such as Hodgkin's disease, leukaemia or lymphosarcoma, are encountered (Herbut, 1952).

The prognosis of the whole sarcoma group is poor and the mortality is high.

\section{Secondary Tumours}

This group of tumours is commoner than the sarcomas. The bladder may be invaded in direct continuity by a tumour in an adjacent organ, such as the cervix or rectum, whilst haematogenous metastases sometimes also occur, but are very rare (Willis, r952).

Quite apart from these rather uncommon tumours, the bladder may also be involved in certain very rare non-neoplastic conditions, such as primary amyloidosis (Franksson, I 950; Beames, 1955) or endometriosis (Baker and Brewer, 1941; Herbut, 1952). 


\section{BIBLIOGRAPHY}

BAKER, W. J, and BREWER, J. I. (194I), Trans. Amer. Ass. gen.-urin. Surg., 34, 135 .

BEAMES, R. P. (1955), F. Urol., 73, 804.

BEGG, R. CAMPBELL (1931), Brit. F. Surg., 18, 422.

BONSER, G. M., CLAYSON, D. B., JULL, J. W., and PYRAH, L. N. (1954), Brit. F. Urol., 26, 49 .

BOREHAM, P. (1956), Ibid., 28, I63.

BOYLAND, E., HARRIS, R. J. C., and HORNING, E. (I954), Brit. 7 . Cancer, 8, 647 .

BOYLAND, E., and WATSON, J. G. (1956), Nature, 177, 837.

BOYLAND, E., and WILLIAMS, D. C. (I955), Biochem. F., 60, v.

BRODERS, A. C. (1922), Ann. Surg., 75, 574.

COOLING, C. I. (1955), 'Carcinoma of the bladder: A clinicopathological study of 100 cases seen at the Royal Marsden and St. Peter's Hospitals.' M.S. Thesis. University of London. As yet unpublished.

DUKES, C. E. (1955), 'The classification of tumours of the bladder -histological grading.' Institute of Urology (University of London) Broadsheet No. I.

DUKES, C. E., and MASINA, F. (1949), Brit. F. Urol., 21, 273.

FRANKSSON, C. (1950), Acta. chir. scand., supplement $15 \mathrm{I}$.

HARNETY, W. L. (1952), 'Survey of Cancer in London.' British Empire Cancer Campaign, London.

HERBUT,' P. A. (1952), 'Urological Pathology.' Henry Kimpton, London:

HOLLANDS, F. (;. (1950), Brit. F. Urol., 22, 34.2.
JEWETT, H. J., and STRONG, G. H. (1946), f. Urol., 55, 366. JOHNSON, F. R. (1957), Brit. f. Lrol., 29, I 12.

KRETSCHMER, H. L., and DOEHRING, P. (1939), Arch. Surg., 38, 274.

MARSHALL, V. F. (1956) 'Bladder Tumors: A symposium. J. B. Lippincott, Philadelphia and Montreal.

McCREA, L. E., and POST, E. A. (1955), Urological Surq ey, 5, 307. C MELICK, W F ESCLE, H. M VARYKA, J. J., MEZERA, R. A., and WHEELER, E. P. (1955), F. Urol., 74, 760.

MELICOW, M. M. (1946), Ibid., 56, 339.

MELICOW, M. M. (1955), Ibid., 74, 498.

MOSTOFI, F. K. (1954), Ibid., 71, 705.

MOSTOFI, F. K. (1957). Personal communication.

PACK, G. T., and Le FEVRE, R. G. (1930), F. Cancer Res., 14, I67

Registrar General's Statistical Review of England and Wales for the year 1954. H.M.S.O., London.

RICHES, E. W., and PAG̈E, B. H. (1956), Brit. F. Urol., 28, 288. SCOTT, L. STUART, and SORBIE, C. (I956), Ibid., 28, 264.

STEINER, P. E. (1954), ' Cancer: Race and Geography.' Williams and Wilkins Co., Baltimore.

WALlaCE, D. M. (1956), Ann. rov. Coll. Surg. Engl., 18, 366.

WHITE, L. L. R. (1952), Report, British Empire Cancer Campaign, 30, 163 .

WILLIS, R. A. (1952), 'The Spread of Tumours in the Human Body.' Butterworth and Co. Ltd., London.

WILLIS, R. A. (I953), 'Pathology of Tumours.' Butterworth and Co. Ltd., London.

\section{When food is intolerable...}

The great charm which Lucozade holds for the invalid palate justifies its use in helping to maintain the level of the blood sugar. Particularly is this so in conditions where all ordinary foods and fluids may be vomited. General medical experience shows that Lucozade is of value wherever the oral administration of glucose is indicated.

\section{- 6}

Lucozade is supplied in $6 \mathrm{oz}$. and $26 \mathrm{oz}$. bottles. It is lightly carbonated with an attractive golden colour and a pleasant citrus flavour. It contains $23.5 \% \mathrm{w} / \mathrm{v}$ Liquid Glucose B.P., and its energy value is $2 \mathrm{I}$ Calories per fluid ounce. 